\title{
Los Ensayos federalistas: pragmatismo e idealismo en la concepción de la Constitución norteamericana
}

Avital Bloch *

\author{
El trasfondo historico
}

En el año de 1987 los Estados Unidos celebraron el bicentenario de la Constitución Federal norteamericana, concluida en la Convención de Filadelfia de 1787. La Convención concibió un documento sin precedentes que definió los conceptos singulares del pueblo estadunidense, de la Unión Norteamericana y del gobierno. Este año trajo consigo la oportunidad de revaluar el documento y de volver a examinar los significa. dos del federalismo. Es ahora preocupación principal de los historiadores norteamericanos ver el trasfondo histórico y los antecedentes de la idea fedéral constitucional. Puesto que se otorga atención especial a la Constitución norteamericana, en México hay razones para tomar nota de ella. Dos son las más importantes: primero, México adoptó como nación el sistema federal y, segundo, el país celebra este año el septuagésimo aniversario de su Constitución de 1917. Así, los historiadores mexicanos pueden aprovechar la oportunidad para reflexionar sobre ambas constituciones y contribuir a un análisis comparativo.

Por mi parte, intento con este ensayo participar en el estudio de cómo nació la Constitución Federal norteamericana. Para ello, a lo largo de estas páginas, analizaré algunos aspectos de la Constitución, a través de una colección de documentos conocida con el nombre de los Ensayos federalistas, ${ }^{1}$ con la esperanza de que el enfoque centrado en esos documentos contribuirá a la comprensión de la Constitución en sí. Los En-

* Centro de Humanidades, Universidad de Colima/Departamento de Historia, Columbia University. Agradezco a Servando Ortoll la traducción de este artículo y a J. Jesús Hermosillo Martín del Campo comentarios y correcciones de estilo a la misma.

1 I Los Ensayos federalistas aparecieron originalmente como artículos seriados en los periódicos neoyorkinos, empezando en octubre de 1787 , poco después de haber sido sometida la Constitución al juicio del pueblo norteamericano. Las intenciones originales de los artículos eran las de influir en la elección de delegados que favorecieran la convención ratificatoria neoyorquina, $y$ la de persuadir a aquellos que se le oponían. Estaban dirigidos "Al Pueblo del Estado de Nueva York" y todos fueron firmados con el seudónimo "Publius". Sin embargo, pronto se supo quiénes eran los autores. Casi todos los ensayos fueron redactados por Madison y Hamilton, excepto unos cuantos redactados por Jay. En la primavera de $\mathbf{1 7 8 8}$, antes de que los últimos ensayos aparecieran en la prensa, la serie completa fue publicada en un libro formado de 85 fascículos. Ha habido un larga disputa alrededor de en quién recae la autoría de varios de los fascículos federalistas. Véase, por ejemplo, Adair Douglass, "The Authorship of the Disputed Federalist Papers", en Trebor Colborn, editor, Fame and the Founding Fathers, Nueva York, W.W. Norton, 1974, p. 27-74. Una discusión basada en análisis estadísticos es la de Frederick Mosteller y David L. Wallace, Interference and Disputed Authorship: The Federalist, Reading, Mass., Addissón-Wesley, 1964. Para este trabajo, utilicé la siguiente edición de los Ensayos Federalistas: Benjamin Fletcher Wright, editor, The Federalist,

Cambrige, Harvard University Press, 1961. Al citar los ensayos por separado, primero doy el número del fascículo en que se encuentran y luego la página en la edición de Fletcher Wright. 
sayos federalistas fueron redactados por Alexander Hamilton, James Madison y John Jay durante la convención de Filadelfia en favor de la nueva Constitución. Estos hombres fueron, sin lugar a dudas, "tres de los más profundos pensadores del periodo", así como tres de los políticos más destacados de la época. Hamilton se graduó en el King's College, era abogado neoyorquino y asistente del general George Washington. Madison, quien realizó sus estudios en la Universidad de Princeton, era político importante en Virginia. Ambos eran jóvenes y miembros prominentes del Congreso en el momento en que fueron enviados a $\mathrm{Fi}$ ladelfia como delegados. Jay, por su parte, graduado igualmente en el King's College y abogado neoyorquino, era secretario de Asuntos Extranjeros cuando tuvo lugar la Convención.

Una mayoría de historiadores y politólogos ha coincidido en que los Ensayos han sido el trabajo más importante sobre la Constitución y el pensamiento político que le dio forma. Para muchos, como para el renombrado historiador Charles Beard, éste ha sido "el trabajo más instructivo en ciencia política jamás escrito en los Estados Unidos", y ocupa un puesto relevante en "la literatura mundial de las ciencias políticas". ${ }^{2}$ El trabajo es importante por su análisis teórico del gobierno y la sociedad. Pero también lo es por su intento de responder a todas las preguntas que norteamericanos de la época se hacían acerca de la nueva Constitución, y por las condiciones que dieron lugar al documento. A pesar de muchas contradicciones y desacuerdos entre los autores, y entre éstos y otros defensores de la Constitución, los Ensayos ayudaron a atraer la atención nacional sobre el débate alrededor de la Constitución. Históricamente, los Ensayos federalistas representan todavía una estructura completa de los valores, principios y motivos de los tratadistas de la Constitución, en un importante periodo histórico de cambio y transicion.

Muchos buenos trabajos han sido dedicados a los Ensayos federalistas. En este escrito se aspira a entender sólo algunos de sus aspectos, limitándose a tratar de demostrar de qué manera, al utilizar la historia y la experiencia humana, los autores de los Ensayos federalistas argumentaban que la nueva Constitución Federal era un documento pragmáti$c o$, anclado en un pensamiento realista. Más aún, se revelará que los federalistas que escribieron el trabajo, a pesar de ser extremadamente pragmáticos, no sacrificaron principios e ideas que estaban profundamente enraizadas en la mente norteamericana. Al forjar una estructura de gobierno innovadora, combinaron experiencia con idealismo.

El éxito del argumento federalista en apoyo de la nueva Constitución Federal se derivó de respuestas prácticas, teóricas y morales que los escritores proporcionaron. El genio del nuevo documento, en su opinión, era capaz de otorgar todas las soluciones mediante un nuevo concepto de unión y gobierno, técnica enraizada en los valores básicos del pueblo norteamericano. La creencia de que los tratadistas de la Constitución habían encontrado formas de conjugar los ideales de la revolución norteamericana con un sentido singular de realismo social y político, convenció a los autores de los Ensayos federalistas de que la

22 Charles A. Beard, "Introduction: Why Study the Federalist Now?" en The Enduring Federalist, Garden City, Nueva York, Doubleday, 1948, p. 10. S6́lo recientemente, los Escritos Federalistas han sido acusados de tener fallas y su validez ya no es automática. Véase Albert Furtwangler, The Authority of Publius: A Reading of the Federalist Papers, Ithaca, Nueva York, Cornell University Press, 1984, p. 17-44. 
Constitución no era simplemente un nuevo documento, sino una guía para crear una "unión más perfecta".

La finalidad de los Padres Fundadores ${ }^{3}$ en 1787 y durante el proceso de ratificación de la Constitución, era persuadir al pueblo de que la situación reinante en los Estados Unidos era la de una crisis profunda derivada directamente de la serie de leyes ineficaces conocidas en su conjunto con el nombre de los Artículos de la Confederación, donde se definía la relación entre los estados y el gobierno central de la Confederación. Esta crisis sólo podía ser dominada, según proponían, construyendo una estructura fundamentalmente nueva para rescatar al país, a la larga, de la inseguridad, la crisis económica y la bancarrota.

En general, el problema durante el periodo posterior a la revolución hasta mediados de la década de los años 1780 - llamado el Periodo Crítico por los historiadores- era una profunda confusión acerca de la legitimidad de imponer autoridad. El problema que afectaba a los individuos, al los estados y al Congreso, tenía varios aspectos. Primero, la relación entre los estados y el Congreso: los Artículos de la Confederación definían al Congreso como la autoridad central sobre todos los estados. En la práctica, sin embargo, el Congreso era casi impotente en su capacidad de imponer autoridad. El problema se había originado en una vaga definición de la Unión, según la cual cada estado mantenía su soberanía y un alto nivel de independencia. Como los estados competían constantemente entre sí en su deseo de favorecer sus propios intereses, el Congreso se topaba con enormes dificultades al trazar políticas centrales y ponerlas en vigor en los estados.

Algunos de los problemas cruciales que el Congreso tuvo que enfrentar fueron económicos. ${ }^{4} \mathrm{Al}$ terminar la guerra de Independencia, la economía nacional se encontraba en su peor condición. La necesidad más urgente del gobierno nacional era llenar las casi vacías arcas del erario. Lo que hubiera parecido simple se convirtió casi en un imposible. Con la inflación creciente de la posguerra, la depreciación del papel moneda y la falta de una unidad monetaria en la Unión norteamericana, se volvio extremadamente difícil restaurar la confianza pública en la capacidad del gobierno para pagar la enorme deuda de guerra, nacional y extranjera, en su valor real. Además, no había ningún acuerdo acerca de sobre quién recaería la responsabilidad de pagar las deudas: ¿Recaería sobre los estados o sobre el gobierno central? ¿Cómo debería determinarse la contribución de cada quién? Constitucionalmente, de acuerdo con los Artículos de la Confederación, el problema era que ninguna institución central podía imponer impuestos a los estados soberanos sin su consentimiento. Se debatió en los estados su participación, y con frecuencia rehusaron pagar. Así, el Congreso, que carecía de capacidad para colectar impuestos, no podía cumplir con sus obligaciones financieras.

Mientras los estados se aprovechaban de su independencia, el comercio y los negocios extranjeros también sufrían enormemente. El Congreso era impotente ante la necesidad de imponer aranceles, regulaciones

3 Este es el nombre con el cual se conoce a los individuos que concibieron y redactaron la Constitucion. Entre ellos se encontraban Madison, Hamilton y Jay.

4 Esta ojeada sobre los problemas económicos anteriores a la Constitución está basada en E. James Ferguson, "The Nationalists of 1781-1783 and the Economic Interpretation of the Constitution", Joumal of American History, núm. 56, 1969, p. 241-261, y Frederick W. Marks, Independence on Trial: Foreign Affairs and the Making of the Constitution, Baton Rouge, I_ouisiana University Press, 1973. 
comerciales y legislación uniformes en toda la nación. Los intentos que hiciera Robert Morris, superintendente de Finanzas, para ganar el apoyo de todos los estados al programa nacional económico, a principios de los años 1780, fracasaron. La Convención de Anápolis de 1786, en la cual nueve de los trece estados participaron,pidió desesperadamente más cooperacion entre los estados respecto a políticas comerciales, pero no logró ninguna solución inmediata.

Ya que la acción conjunta de los estados y el Congreso no podía ser alcanzada, la seguridad nacional y la diplomacia ante el exterior estaban en peligro. Ningún control central sobre relaciones extranjeras podía obtenerse mientras los estados mantuvieran intereses separados. Ningún convenio, pacto, o arreglo podía ser firmado por el Congreso. El ejército tampoco se encontraba a salvo. ¿Quién financiaría a un ejército insuficientemente equipado? Más aún, ¿quién podía tener autoridad sobre él, en caso de conflictos armados y, por otro lado, podía ser utilizado en contra de estados individuales? No había consenso sobre como responder a estas preguntas.

Los celos acalorados entre estados también tomaron forma de lucha por tierras ociosas en el oeste. ${ }^{5} \mathrm{El}$ deseo de los estados de expandirse aun a costa uno del otro, causaba un miedo tangible de guerras fronterizas entre ellos. ${ }^{6}$ El Congreso estaba en la imposibilidad de promover el reconocimiento mutuo y la reglamentación de las reclamaciones territoriales. Los Artículos de la Confederación no proveían reglas y mecanismos para crear de nuevo estados y admitirlos en la Unión norteamericana.

La atmósfera caótica y la impotencia del Congreso durante el Periodo Crítico desalentaron cualquier impulso de los estados de cooperar en una causa nacional común. La conclusión de los federalistas era que el principio de la soberanía del estado iba en contra del ideal patriota inicial de la Unión norteamericana, que se enfrentaba a un serio peligro de extinción. Pero los severos conflictos sociales en la década de 1780 también amenazaron la unidad nacional y demostraron con más fuerza el problema de una falta de legitimidad en la Confederación. Como parte de una corriente que demandaba imparcialidad y representación real en las instituciones gobernantes, la gente de la frontera, ${ }^{7}$ con frecuencia granjeros endeudados que luchaban por la supervivencia, protestaba contra su exclusión del contrato social. Rehusaban someterse a la autoridad de las legislaturas del Estado que para ellos simbolizaba a las privilegiadas clases altas gobernantes de cuya legitimidad recelaban.

Era necesario atender inmediatamente el asunto de la delimitación de la autoridad, particularmente desde 1786, cuando la rebelión dirigida por Daniel Shays, un excapitán militar, demostró la fragilidad de la autoridad. Los rebeldes eran casi 2000 endeudados agricultores pobres del occidente de Massachusetts. Incapaces de pagar sus hipotecas, amenazaron violentamente un arsenal federal y obligaron al cierre temporal de las cortes. A pesar de que la insurreción fue derrotada por tropas

5 La colonización en la frontera occidental significo expansión en los territorios indios, misma que resultó en batallas sin fin en contra de estos últimos.

6 Véase, sobre la competencia entre estados, Peter Ónuf, The Origins of the Federal Republic: Jurisdictional Controversies in The United States, 1775-1787, Filadelfia, University of Pennsylvania Press, 1983.

7 La frontera se define aquí como las nuevas áreas de colonización más al oeste y alejadas de las viejas ciudades centrales. Estas áreas constituían la periferia y estaban caracterizadas por su economía rural. 
militares, las acciones violentas de las multitudes amenazaron aquellos elementos de la sociedad que acostumbraban pensar que poseían la autoridad social y política. La clase elitista sintió la urgencia de someter a las masas a la ley y al orden. Así, mientras que los whigs ${ }^{8}$ en la década de 1770 habían dependido comúnmente de la acción popular extralegal, en la de $\mathbf{1 7 8 0}$ las masas fueron identificadas por su potencial anárquico y tiránico. Los Artículos de la Confederación eran ineficaces para controlar tales acciones, pues carecían de una definición del contrato comunal y de quién se suponía que había de obedecer a las autoridades. ${ }^{9}$

La crisis en todos sus aspectos demostró a muchos norteamericanos que, a menos que se llegara a acuerdos sobre reformas radicales, se convertiría en un desastre que podría destruir todos los logros de la revolución norteamericana. Parecía urgente rescatar la unidad: "Se puede ciertamente decir con propiedad que casi hemos alcanzado la última etapa de la humillación nacional", escribio Publius. ${ }^{10} \mathrm{Al}$ principio se intent 6 reformar las constituciones de los estados. Sin embargo, la presión creada por problemas sociales y políticos y la obvia impotencia de los estados para restablecer ellos mismos la autoridad, hizo que la discusión se convirtiera en nacional. La Convención de Anápolis de 1786 fue convocada en el momento en que la mayoría de la gente reconocía la necesidad de reformas radicales. La importancia inicial de Anápolis era que señalaba a la conciencia de los federalistas que todos los problemas estaban relacionados con el principio de legitimidad y soberanía, y que sólo podían encontrar la solución integral en los cambios constitucionales. Por lo tanto, el fracaso inmediato de esta convención en lograr la cooperación comercial urgente entre los estados, resultó benéfica, ya que alentó a la Convención Constituyente de Filadelfia a recomendar reformas constitucionales de gran envergadura. ${ }^{11}$

Como resultado de un compromiso, se completó la concepción de la Constitución Federal en Filadelfia. El debate entre los federalistas y los antifederalistas fue duro y se tradujo en algunos logros importantes de los antifederalistas. Sin embargo, el triunfo mayor fue el de los federalistas. Su idea nacional federal fue aceptada como el principio fundamental de la nueva Constitución. Mientras el federalismo presentaba soluciones a lo que sus seguidores identificaban como necesidades urgentes para salvar a la Unión, también se hacía eco de una alteración importante en la ideología política de los whigs, proveniente de la era revolucionaria. Por lo tanto, la Constitución indico el clímax de una gran revolución. Los norteamericanos creían que la Constitución remediaba casi todos los defectos de las constituciones anteriores de los estados y los Artículos de la Confederación. Sintieron que lograron algo extraordinario en la historia política: un experimento totalmente nuevo en materia de gobierno, basado en una integración de principios y experiencias universales y particulares. ${ }^{12}$

8 Asf́ se llamaba a los "radicales" que lucharon por la independencia de las colonias de Inglaterra durante el periodo revolucionario norteamericano. Recibieron su nombre del grupo de oposicion en Inglaterra.

9 Gordon S. Wood, The Creation of the American Republic, 1776-1787, Nueva York, W.W. Norton, 1969, p. 282-291, 319-328, 363-372, 409-413; Yehoshua Arieli, Individualism and Nationalism in American Ideology, Cambridge, Harvard University Press, 1964, p. 33-37.

10 Fletcher Wright, op. cit, núm. 15, p. 156. Para la explicación de la forma en que cito los Ensayos federalistas, véase el pie de página núm. 1.

11 Wood, op. cit., p. 393-403, 463-467.

12 Wood, op. cit, p. 593-596. 


\section{Sobre el concepto histórico}

Más allá de las ideas de los filósofos europeos de la Ilustración, que utilizaron para dar forma a su propio pensamiento político, los norteamericanos encontraron también un gran auxiliar en la historia. En Europa, la moda durante los siglos XVII y XVII era confirmar, con evidencias historicas, las conclusiones a las que se había llegado por el pensamiento racional. ${ }^{13}$ Cuando la historia se usaba para confirmar posiciones y opiniones, era por el método deductivo. El procedimiento de deducción consistía en tomar ejemplos de experiencias pasadas, haciendo una generalización deductiva y llegando a conclusiones aplicables para el presente o para el futuro. Se asumía que basándose en el conocimiento del pasado se podían hacer deducciones y predecir los sucesos de cualquier momento futuro, en circunstancias similares a la situación histórica.

Los autores de los Ensayos federalistas fueron atraídos por este método. Esperaban que al usarlo, podrían alcanzar su finalidad pragmática. El pensamiento pragmático se asentaba en la confianza de que, al escrutar el pasado de gobiernos históricos, el sistema político que sugerían podría evitar los escollos de gobiernos y constituciones pasados. Así, el aprender lecciones de experiencias históricas y aplicarlas como conclusiones verdaderas en las cuestiones políticas del día, se convirtió en el fundamento racionalizador de los Ensayos federalistas: "Nuestra finalidad" es "evitar los errores sugeridos por la experiencia pasada de otros países, así como de la nuestra, y proveer un modo conveniente para [rectificarlos], tal y como la experiencia futura puede revelarlos. Podemos obtener ventajas de la experiencia [de otros países] sin pagar cl precio que les costó a ellos." 14

Ese concepto de aprender "lecciones de ése, el mejor oráculo de la sabiduría, la experiencia", ${ }^{15}$ fue difundido durante el Periodo Crítico y la Convención Constitucional. ${ }^{16}$ Esto no debe sorprendernos. Para los federalistas, como hijos de la edad del realismo, parecía más real depender de "axiomas" eternos y principios universales acerca del hombre y del gobierno, que depender de utopías e ideologías fijas. Prefiriendo fundamentos objetivos de causalidad, los Padres Fundadores abogaban por utilizar la experiencia como el único método causal seguro, racional y objetivo. Ellos creían que el método era la base de una "ciencia" absoluta que podía ser aplicada universalmente. Su finalidad era demostrar que la política y el gobierno no solamente pueden, sino que deben ser fundados en tal ciencia. ${ }^{17}$

También aprendiendo de acontecimientos históricos experimentados por ellos mismos, los federalistas de la década de 1780 preferían la ciencia metodológica a la ideología. Esta preferencia se debía a la forma en que la ideología había sido utilizada tanto durante la crisis revolucionaria de la década de 1770, como durante el Periodo Crítico de la de 1780. Según ellos, la lección que habían aprendido era que en todos los perio-

13 Martyn P. Thompson, "A Note on Reason and History", en Political Theon, núm. 4, 1976, p. 491-504.

14 Ibidem, núm. 37, p. 267; núm. 5, p. 105.

15 Ibidem, núm. 15, p. 160 .

16 Douglass Adair, "Experience Must Be Our Only Guide: History, Democratic Theory, and the United States Constitution", en Adair, op. cit, p. 108-110. Adair presenta ejemplos de esa visión de John Adams, John Dickinson, James Wilson y otros.

17 John M. Werner, "David Hume and America", en Joumal of the Histony of Ideas, núm. 33,1972 , p. 440 . 
dos los radicales habían tendido a depender de planes utópicos ideologicos y de conceptos abstractos formulados a priori para suscitar el radicalismo y el antiautoritarismo por los cuales habían justificado sus acciones extremas y excitado a las masas. ${ }^{18}$ En la mente de aquellos que durante la agitación de la década de los años 1780 esperaban restaurar la ley y el orden, tales tendencias fueron tachadas de provocar actividades peligrosas en las multitudes.

La búsqueda de patrones constantes y de procesos en la sociedad y la política para llegar a conclusiones científicas, fue intensificada en los Estadōs Unidos especialmente durante los años 1780. En la búsqueda por medio del pragmatismo, la fuente principal de influencia era la Escuela Escocesa del Sentido Común en la Universidad de Edimburgo, la cual estaba dirigida por los filosofos David Hume, Adam Smith y Adam Ferguson. El supuesto básico de estos filósofos era que la naturaleza humana permanece siempre idéntica en sus principios y en las formas con que impulsa al hombre. Este supuesto llevo a esos teóricos a la investigación social y a la recolección metódica de sucesos históricos cuya finalidad era probar la existencia de uniformidad en las acciones humanas, en todas las naciones y en todos los tiempos.

Así, mientras el pensamiento social y político norteamericano se nutría de las teorías de Locke, Hobbes, Montesquieu, Rousseau y Voltaire, los Padres Fundadores estaban muy influidos por los escoceses. Ya durante la Colonia, los tratados escoceses se habían generalizado como libros de texto en las universidades norteamericanas donde los estudiantes se entrenaban en el concepto del Sentido Común de las ciencias sociales. Conexiones cercanas habían sido especialmente mantenidas entre la Universidad de Princeton y los pensadores de Edimburgo, y allí se originaron los esfuerzos para extender sus teorías en los Estados Unidos. ${ }^{19}$ Pero era especialmente Hume, en su perfección de la idea de la historia como la fuente más importante para la "ciencia de la política", quien se convirtio en modelo para los autores de los Ensayos federalistas. Madison y Hamilton utilizaron claramente algunas de sus ideas más importantes, aunque su nombre, a diferencia de los nombres de otros filósofos, no aparece en el texto de los Ensayos. En otros lugares, sin embargo, la admiración parecía ser científica. Hamilton, por ejemplo, hablaba de Hume como "un autor célebre" y como "uno de los políticos más hábiles". ${ }^{20}$ Madison, graduado en la Universidad de Princeton, también se convirtió en un ardiente discípulo de Hume. ${ }^{21}$

18 John Patrick Diggins, The Lost Soul of American Politics: Virtue, Self-Interest, and the Foundations of Liberalism, New York Basic Book, 1984, p. 86-87. Esta idea sigue la tesis originaria [seminal] de Bernard Bailyn. Véase Bernard Bailyn, The Ideological Origins of the American Revolution, Cambridge, Harvard University Press, 1967.

19 El hecho de que nueve de los delegados de la Convención se graduaron en la Universidad de Princeton, afectó sus modos "científicos" de argumentar. Usaban con frecuencia expresiones tales como "la experiencia demuestra" o"la historia prueba" en formas bastante identicas a los escritos federalistas. Véase Douglass Adair, "That Politics May Be Reduced to a Science. David Hume, James Madison, and the Tenth Federalist", en Adair, op. cit., p. 94-97; Adair, “Experience”, p. 110.

20 Theodore Draper, "Hume and Madison: The Secrets of Federalist Paper No. 10", Encounter, núm. 58, 1982, p. 37-40.

21 El primero en señalar la influencia de Hume en Madison fue Adair en sus dos artículos, "Politics" y "Experience". Wills subraya más la atracción de Hamilton hacia Hume. Vease Gary Wills, Explaining America: The Federalist, Garden City, Nueva York, Doubleday, 1981, p. 66-74. Véase también Roy Bronson, "James Madison and the Scottish Enlightenment", Journal of the History of Ideas, núm. 40, 1979, p. 235-237; Werner, op. cit., p. 451-453. 
Los logros científicos de Hume y su grupo señalaron para Publius las nuevas posibilidades de aplicar la ciencia política a las políticas de su tiempo. Como resultado de esta influencia se pueden seguir las similitudes en estructura y argumentación entre los escritos de Hume y los Ensayos federalistas. Aceptando el planteamiento de Hume de que "la política puede ser reducida a una ciencia", ${ }^{22}$ Publius expresó el optimismo de los federalistas acerca de las ventajas de las predicciones científicas en la política: "La ciencia de la política, sin embargo, como Ia mayoría de las demás ciencias, ha mejorado ampliamente. La eficacia de varios principios se entiende bien ahora y, o bien no eran conocidos en lo absoluto, o eran conocidos imperfectamente por los antiguos." ${ }^{23}$

Como Hume, los federalistas consideraban la historia como una ciencia social, pero con frecuencia la igualaban, tal como él lo había hecho, con las ciencias naturales. Los resultados para ellos, como en las ciencias naturales, pueden siempre predecirse basándose en verdades objetivas. ${ }^{24}$ Hume escribio: a través de documentos históricos "el político o filosofo moral fija los principios de su ciencia, de la misma manera en que el médico o filosofo natural se familiariza con la naturaleza de las plantas, los minerales y otros objetos externos, por medio de experimentos que concibe con respecto a ellos". Las predicciones basadas en la historia, convencio Hume a los norteamericanos, son "casi tan generales y seguras ... como cualquiera que la ciencia matemática nos suministre". ${ }^{5}$ Aplicar el pensamiento científico y enfocar la conducta social en patrones fijos, como la naturaleza, permitía a los federalistas pensar en el gobierno y la sociedad en términos de mecanismos de estructuras sociales más que en seres humanos. Lo que ilustra esto son los términos que Publius tomó prestados de las ciencias naturales para referirse al gobierno: "orbita", "esfera", etcétera.

Durante el periodo constitucional, la consecuencia importante del apego de la gente a predicciones "científicas" incuestionables era una actitud determinista. Esta tendencia refleja un cambio de la vieja tradicion ilustrada whig. Los federalistas repudiaban el entusiasmo profundo usual de la Ilustración acerca del progreso, ideología y espíritu humano, y su capacidad de reformar y cambiar a la sociedad. Los federalistas introdujeron la creencia de la repetición de la historia y de la función mecánica predecible de la sociedad. La consecuencia fue ignorar la naturaleza evolutiva de la historia, y la confianza en las instituciones y en sus principios operantes repetitivos. ${ }^{26}$

La preferencia de los proponentes de la nueva Constitución a depender de las instituciones, puede ser entendida en relación con su finalidad de restaurar el orden social. Podían probar, con la "ciencia" que, en oposición a las acciones anárquicas e impredecibles de las masas, las instituciones centrales del sistema político son más confiables por su predecible función ordenada. Y en obsequio a su campaña en favor de la Constitución, el argumento general histórico científico de los Padres Fundadores les permitía demostrar que el documento propuesto no era

22 Véase Ađair, "That Politics...", p. 96.

23 Fletcher Wright, op. cit, núm. 9, p. 125.

24 Diggins, op. cit., p. 86-87, 89-91.

25 Citado en Adair, "That Politics...", p. 96.

26 Diggins, op. cit, p. 66-68; Adair, "Experience", p. 113; Arieli, op. cit, p. 108-110; Norman Jacobson, "Political Realism and the Age of Reason: The Anti-Rational Heritage in America", Review of Politics, núm. 15, 1953, p. 446-447, 449-450. 
utópico sino, por el contrario, viable, con base en un resumen de la totalidad de las leyes universales evidenciadas por la historia. ${ }^{27}$

\section{Sobre la naturaleza del hombre}

El método que Publius adoptó de Hume estaba basado en un supuesto acerca de la uniformidad de las acciones humanas en la historia. Hume escribio:

Hay una gran uniformidad entre las acciones de los hombres en todas las naciones y edades, y la naturaleza humana permanece todavía la misma, en sus principios y operaciones. Los mismos motivos siempre producen las mismas acciones; los mismos acontecimientos siguen a las mismas causas ... La humanidad es a tal grado la misma, en todos los tiempos y lugares, que la historia no nos informa sobre nada nuevo o extrano en este particular. Su uso principal es solamente descubrir los principios constantes y universales de la natuleza humana, presentando a los hombres en todas variedades y situaciones, y proporcionándonos materiales con los cuales podamos formar nuestras observaciones y familiarizarnos con los resortes regulares de la acción y conducta humana. ${ }^{28}$

Era esencial para Publius descubrir los principios repetitivos de la naturaleza humana en la forma que se manifestaron a través de la historia en obsequio de la teoría, y por razones prácticas. Teóricamente, las nuevas ciencias sociales prescribian que la sociedad y las instituciones, incluyendo las instituciones gubernamentales, tenían que ser entendidas en términos de grupos de gente como estructura. Ideológicamente, la concepción de gobierno de los federalistas estaba fundada en el consentimiento popular; de esta manera, si la finalidad era la de obtener armonía entre pueblo y gobierno, los federalistas tenían que estudiar y tomar la naturaleza humana en consideración. ${ }^{29}$ Así, siguiendo a Hume y sus propias observaciones históricas, Publius llego a concluir que el carácter humano es negativo y no confiable. El hecho de la existencia de una naturaleza negativa, sin embargo, ayudó a justificar la preferenccia hacia la dependencia en instituciones organizadoras del orden social y a convencer acerca de las formas en que las recién propuestas instituciones manejarían la mala naturaleza del pueblo. La mejor forma de persuadir, pensaron los autores de los Ensayos federalistas, era demostrar que lo que había causado la ruina de gobiernos anteriores con instituciones constitucionales débiles, era la gente misma.

Caracterizó la percepción de Publius sobre la desventajosa naturaleza de los seres humanos la idea de que no puede ser cambiada. Para él

27 Esta convicción también influyó en el estilo de los escritos federalistas a los cuales tachaban de objetivos. Se esperaba que el candor y la falta de interés como tácticas convencerían. Los autores afirmaban no estar prejuiciados y sí ser honestos, de criterio amplio y defensores de la verdad, mientras que incuestionablemente las leyes científicas de la historia los respaldaban. Asumían la posición de un juez: con frecuencia presentaban una alternativa y afirmaban que la elección verdadera era científicamente clara. Se creía que tales técnicas creaban su autoridad y la impresión de que ellos se elevaban por encima de las luchas políticas constitucionales. Veáse Furtwangler, op. cit., p. 61-69; y Wills, op. cit., p. 21-23.

28 Citado en Adair "That Politics...", p. 95.

29 Richard Hofstadter, "The Founding Fathers: An Age of Realism", en Richard Hofstadter, The American Political Tradition and the Men Who Made It, Nueva York, Vintage Books, 1948, p. 7; Martin Diamond, Notes on the Political Theory of the Founding Fathers, Filadelfia, Temple University, documento de trabajo núm. 10, 1971, p. 9. 
dicha naturalèza es constante porque las desventajas no son cuestión del libre albedrío del hombre, sino que están enraizadas como tendencia en la naturaleza. El elemento fundamental en la naturaleza del hombre es lo que Publius comúnmente llamaba "intereses", "intereses propios", o "pasiones" que impulsan las acciones del hombre. Publius apuntó hacia la mayoría de las pasiones, tales como los celos, el egoísmo, la ambición y el odio, como intereses viciosos cuya característica principal es un deseo egoísta del hombre de alcanzar poder e influencia para sí, sin tener en cuenta la virtud y el bien común. Por lo tanto, la más grande preocupación de los autores de los Ensayos federalistas era que los conflictos de los intereses privados frente al interés público pudiesen destruir potencialmente a todo el Estado. ${ }^{30}$

Varias fuentes pueder ser rastreadas en la vision negativa del hombre de los Ensayos federalistas. Primero, con base en su experiencia inmediata, sus autores observaron que los norteamericanos no deseaban cooperar unos con otros, sino que competían sobre cada recurso del país, rebelándose en contra de la autoridad, estableciendo clases y rehusando hacer concesiones en aras del bien común. El miedo de las multitudes, especialmente, encauzaba a los federalistas a asociar a la gente con acciones egoístas, extremas, violentas, irracionales e irresponsables. La inestabilidad entre las masas y la amenaza a la autoridad parecía una pérdida de virtud en los Estados Unidos y trajo consigo las conclusiones de que los intereses debían ser explicados en términos de pasiones. Sin embargo los federalistas no excluían de la historia la situación del momento, particularizándola, sino que concluían que evidentemente la pasion y el mal han sido características uniformes en el hombre durante siglos de historia. ${ }^{31}$

La añoranza de la virtud puede ser entendida en el contexto del legado whig del siglo XVIII en los Estados Unidos. La década de los años 1770 tendía a resaltar las ideas clásicas de virtud, que incluían autocontrol, deber y entrega al interés público. Durante la revolución norteamericana, éstos fueron principios importantes que alentaron la protesta en contra de la corrupción británica en la madre patria y en las colonias y motivaron el radicalismo de los patriotas. Sin embargo, la virtud fue insuficiente para enfrentarse a la crisis de la autoridad interna en la década de 1780. La virtud era ineficaz para inspirar a la gente un espíritu de entrega, y en opinión de los Padres Fundadores parecía ciertamente haber desaparecido de entre las masas. ${ }^{32}$

No obstante, en los Ensayos federalistas, las virtudes aparecían combinadas con los intereses. Estos se representaron como intereses que operan más armónicamente con el bien público. Están relacionados con valores morales elevados, tales como patriotismo, deber y justicia. ${ }^{33}$ Pero los autores lamentaban que solo pudieran encontrarse en una elite minoritaria de norteamericanos "sabios, sistemáticos y juiciosos", libres de intereses propios, e "interesados individualmente en la libertad pública y en la prosperidad". ${ }^{34}$ Como mejor ejemplo se re-

James P. Scanlan, "The Federalist and Human Nature", Review of Politics, núm. 21, 1959 , p. $660-665$.

31 Adair, "Experience...", p. 120.

32 - Wood, op. cit., p. 53-57, 68-69, 98, 609-610; Diggins, op. cit., p. 31-32. La idea de utilizar la creencia en la corrupción británica durante la revolución es parte central de la tesis de Bailyn. Véase Bailyn, op. cit., p. 94-159.

33 Scalan, op. cit, p. 660-665.

34 Fletcher Wrigh, op. cit., núm. 3, p. 98; núm. 2, p. 96. 
ferían a los delegados de la Convención, cuya distinguida virtud los había liberado de cualquier pasión y no los dirigía hacia ningún interes, "excepto el amor por su país". ${ }^{35}$ En otros casos, sin embargo, la mala naturaleza del hombre es universal.

Ayudó a los Padres Fundadores a concluir acerca de la universalidad de la desventaja en el carácter del hombre el acento calvinista tradicional sobre la pecaminosidad humana. El puritanismo norteamericano veía a los seres humanos como un átomo de interés individual, así que los puritanos proyectaron un sistema social para supervisarlos. Los federalistas agregaron a esa tradicion la sustentación de realismo y ciencia, afirmando que era imposible cambiar la naturaleza humana. ${ }^{36}$

Las fuentes europeas sobre la idea del carácter negativo del hombre incluyen - además de Maquiavelo, quien primero expresó opiniones sobre las pasiones del hombre-a los filosofos de la Ilustración. A pesar de la fe básica de la llustración en el hombre, se mantenían pensamientos acerca de su naturaleza defectuosa. Por ejemplo, Hobbes veía al hombre como un ser irracional en su ansia de poder. Su influencia en los federalistas fue fuerte. Ellos tambien estaban conscientes de los problemas de Locke en relación con el egoísmo del hombre. ${ }^{37}$ Pero de nuevo, parece que Hume ejerció la mayor influencia sobre Publius en relación con el carácter negativo del hombre, especialmente en relación con las funciones del gobierno. Las pasiones humanas, los deseos y los intereses eran una preocupación principal para Hume, particularmente porque él las entendía como una condición natural, y no como desviación que pudiera ser corregida. Influyó en sus discípulos en los Estados Unidos para que aceptaran al hombre tal como se conduce realmente, no como debería comportarse, y a no esperar de él cambios voluntarios. ${ }^{38}$ Publius lo repitio con estas palabras: "las pasiones de los hombres no se conformarán a los dictados de la razón y la justicia sin represión". 39

El periodo moderno en su totalidad, en la filosofía política occidental, no estaba alejado de la visión de un hombre lleno de pasiones, egoísta y con ansia de poder. Este pensamiento siguio el marco conceptual de los "derechos naturales", según el cual el interés individual hace del hombre un ser antipolítico y antisocial. Naturalmente, tiende a no respetar las restricciones, por lo tanto el Estado y las leyes son extranaturales y tienen que ser creadas y reforzadas artificialmente. La única cosa natural, de acuerdo con esta idea, es el derecho del hombre a la libertad, es decir, el derecho a proseguir sus intereses. ${ }^{40}$ Siguiendo este concepto, Hobbes arguyó que el hombre sólo puede aceptar restricciones voluntariamente. Una persona puede renunciar a un derecho natural y al interés propio sólo cuando llega a un estado de razón. Y llega a

35 Ibidem, núm. 2, p. 95. Para una discusión sobre el concepto elitista de los federalistas, véase Cecilia Kenyon, "Alexander Hamilton: Rousseau of the Right", Political Science Quarterly, núm. 73, 1958, p. 163-164.

36 Hosfstadter, "The Founding Fathers...", p. 4, 7; Diggins, op. cit., p.79.

37 George Mace, Locke, Hobbes, and the Federalist Papers: An Essay on the Genesis of the American Political Heritage, Carbondale, Illinois, Southern Illinois University Press, 1979, p. 48-52.

38 Diggins, op. cit, p. 70-71; Wills, op. cit., p. 84.

39 Fletcher Wright, op. cit., núm. 15, p. 160.

40 La idea de "derechos naturales" difería de la idea clásica de "ley natural" donde filosofos griegos, romanos y medievales concordaron con que la naturaleza humana es primordialmente razonable y altruista. Se entendía básicamente a los individuos como criaturas sociales y políticas. Así, el gobierno, la ley y las instituciones sociales no están forzadas en la sociedad, sino que son naturales. Véase Mace, op. cit., p. 3-7, 56-57. 
ese estado cuando entiende que tiene el privilegio de renunciar a sus derechos por su propio beneficio, o a cambio de alguna recompensa. Tal es el caso, por ejemplo, de la gente que se da cuenta de que sus pasiones pueden causar la guerra. Así, para asegurar la paz en beneficio de todos los individuos, en los términos de sus propias vidas y seguridad, estarían de acuerdo en abandonar algunos de sus derechos a un gobicrno comprometido a proteger la vida y la paz. ${ }^{41}$

Así, al discutir el carácter del hombre, la edad de la razón no desechó a la razón por completo. Pero la razón estaba colocada dentro del marco de aceptación del interés propio del hombre como su derecho de posesión, rechazando aseveraciones de que él es capaz, o debería sèrlo, de pasar por cambios si éstos no lo benefician. De ahí que los Ensayos federalistas desconfiaran de la razón y de los buenos deseos de los individuos para derrotar fácilmente el interés propio y cultivar un espíritu de armonía y concordia:

\begin{abstract}
¿No se ha encontrado ... invariablemente que las pasiones momentáneas y los intereses inmediatos tensan un control más activo y dominante sobre la conducta humana que consideraciones generales o remotas de política, utilidad, o justicia? ... iNo hemos ya visto bastante falacia y extravagancia en aquellas teorías inútiles que nos han entretenido con promesas de exención de imperfecciones, debilidades y males incidentes en la sociedad en toda forma? ¿No es ya tiempo de despertar del suef́o falaz de una edad de oro, y adoptar como máxima práctica para la dirección de nuestra conducta política que nosotros, como los demás habitantes del globo, estamos todavia alejados del feliz imperio de la sabiduría y la virtud perfectas? ${ }^{42}$
\end{abstract}

A pesar de su añoranza de la virtud, los federalistas eran ambiguos acerca de su significado. Dado que la virtud había sido una poderosa idea revolucionaria utilizada en la década de los años 1770 como motivación ideológica, los federalistas sospechaban en ella una retorica antiautoritaria radical y peligrosa. De esta forma, aunque la virtud y la razón eran fundamentalmente deseables, los federalistas se vieron forzados a ignorarlas como cualidades con poder suficiente para dirigir a la gente durante los días turbulentos del Periodo Crítico. Como ideas, la virtud y la razón avivan las pasiones que tiranizan la capacidad del hombre de razonar, y por tanto contienen demasiado riesgo. Así, si los Padres Fundadores eran ligeramente optimistas en relación con la virtud, ésta no fue adquirida de su fe en la razón, sino de su fe en la ciencia. Cuando se vieron enfrentados con el problema de convencer al pueblo norteamericano para que subordinaran algunos de sus derechos e intereses privados en aras del bien común, los federalistas entendieron que esto debía hacerse utilizando la ciencia y no las ideas. Esperaban que explicar los principios científicos de la naturaleza humana fuese el mejor medio para guiar al pueblo en la dirección correcta hacia la razón. ${ }^{43}$

Ideas y virtud, concluían los Ensayos federalistas, no pueden compeler al hombre a menos que sean explicadas científicamente en términos de intereses. La virtud puede ganar, pero no como resultado de una lucha entre los poderes de la razón y la pasión. Por el contrario, 
como lo sugirió Hobbes, el hombre abandonará algunos de sus intereses en aras del bien común cuando descubra, mediante la razón, que el sacrificar el interés de uno será benéfico para otros intereses. 44 Sin embargo, los autores de los Ensayos federalistas reconocieron que de todas formas la virtud de la razón es necesaria para ayudar al hombre a revaluar las prioridades de sus intereses. Puede decirse que los autores entendieron la razón en términos de utilizar un "interés propio" como defensa en contra de otro "interés propio". ${ }^{45}$

\section{Acerca de facciones}

El fenómeno más severo que resultó de la naturaleza apasionada del hombre fue lo que los Ensayos federalistas llamaron "faccion". Publius definio una "facción" como

un número de ciudadanos, ya sea que sumen la mayoría o minoría del todo, que están unidos y animados por algún impulso común de pasión o de interés, adverso a los derechos de otros ciudadanos, o a los intereses permanentes o globales de la comunidad. ${ }^{46}$

De esta forma, Publius concebía la facción como un grupo de personas unidas por un común y apasionado interés propio que opera en contra del interés común. El énfasis era que una facción es una manifestación colectiva del vicio del hombre:

¿Se ha descubierto acaso que grupos de individuos actúan con más rectitud o mayor desinterés que los individuos aislados? Lo contrario ha sido inferido por todos los observadores certeros de la conducta humana. ${ }^{47}$

Lo que hizo que las facciones fueran un fenomeno importante para los federalistas fue su origen, $y$ la facilidad con la cual las facciones se crean y existen perennemente:

las causas latentes de la facción son, de esta forma, inherentes a la naturaleza del hombre... Tan fuerte es la propensión de la humanidad a caer en animosidades mutuas, que aún cuando ningún motivo real se presente, las distinciones más frívolas y caprichosas han sido suficientes para encender sus pasiones poco amistosas y excitar su conflicto más violento. ${ }^{48}$

Por lo tanto, "las causas de la facción no pueden ser eliminadas". 49

Por su antipatía hacia las facciones, es claro que los Padres Fundadores no simpatizaban con cualquier noción de partido, lo cual reflejaba

\footnotetext{
44 Diggins, op cit., p. 24-31, 97-98; para una visión distinta, que resalta la lucha entre el bien y el mal, véase: Scanlan, op cit., p. 660-665.

45 Meynard Smith, "Reason, Passion and Political Freedom in the Federalist", Journal of Politics, núm. 22, 1960, p. 525-526, 541-542.

46 Fletcher Wright, op. cit., núm. 10, p. 130.

47 Ibidem, núm. 15, p. 160.

48 Ibidem, núm. 10, p. 131. Es fácil rastrear aquí la influencia de Hume en Madison. Hume escribi6: "Los hombres tienen tal propensión a dividirse en facciones personales, que la más pequeña apariencia de diferencia real las producirá." Citado en Adair, "Politics", p. 103.

49 Fletcher Wright, op. cit., núm. 10, p. 131
} 
su intolerancia a las diferencias en opiniones políticas. ${ }^{50}$ Esta tendencia estaba relacionada con su concepto del bien común. Se suponía que la gente debía ser homogénea en sus intereses: lo que es bueno para la comunidad es bueno para cada individuo o grupo. A pesar de haber notado la existencia de partidos e intereses en conflicto, los federalistas los consideraban ilegitimos. ${ }^{51}$ Por 10 tanto, deseaban vehementemente restringir y eliminar las facciones, pues creían que al hacerlo derrotarían la fuente del mal en la sociedad política.

Tal como lo hicieron en relación con la naturaleza humana, los autores de los Ensayos federalistas derivaron gran parte de su visión acerca de las facciones de David Hume, quien tachaba a la oposición de facción basado en su experiencia en los conflictos de partidos en Inglaterra. Explicaba la existencia de facciones por la falta de escepticismo de la gente, cuya tendencia es no dudar de sus ideas, de tal forma que su certidumbre la hace sentirse siempre del lado de la razon y ansiosa de imponer sus ideas. Sin hacer caso al interés común, escribio Hume, las facciones dieron pábulo a la violencia y desgarraron a la nación. ${ }^{52}$ Durante el siglo XVIII, Hume se opuso al County Party (Partido del Condado), el cual era el partido de oposición en Inglaterra. Es interesante saber que este partido inspiró la posicion radical de los patriotas norteamericanos en contra de los ingleses antes de la revolución. Así es que el hecho de que los federalistas adoptaran en la década de 1780 el rechazo de Hume a la oposición puede ser visto como una reacción conservadora en contra de la crítica política y en defensa de la sumisión a la autoridad establecida. ${ }^{53}$ Nuevamente, si consideramos el temor que existía durante el Período Crítico hacia los extremos populares, la identificación de los federalistas con el conservadurismo de Hume no es sorprendente. ${ }^{54}$

De la misma forma que Hume sospechaba de la mayoría de las "facciones de principio", es decir de las facciones involucradas con ideas abstractas y especulativas, Publius temía también su estusiasmo por diferentes opiniones relacionadas con religión, gobierno y "muchos otros puntos". 55 El entusiasmo que controla la conducta de tales partidos está relacionado con aquello a lo que Publius se refería como "pasiones momentáneas" e "intereses inmediatos", en oposición a "consideraciones remotas de programa político, utilidad o justicia". 56 Los autores querían señalar la carencia de sofisticación y del suficiente distanciamiento de los problemas que demuestran tener las facciones extremas en su crítica política. Para los federalistas, sin embargo, un enfoque políticamente mucho más complejo era considerado ideal para tener un juicio medido y responsable.

A pesar de que Publius se refería a una facción, ya sea como facción de las minorías o de las mayorías, los Ensayos federalistas dejaban en claro que lo que preocupaba a sus autores era la facción mayoritaria. Al

50 Sobre el problema de ilegitimidad, vease Richard Hofstadter, The Idea of a Party System: The Rise of Legitimate Opposition in the United States, Berkeley, California, University of California Press, 1964, p. 40-73.

51 Wood, op. cit.,p. 57-60, 63-65.

52 Adair, "Politics," p. 97-106; Wills, op. cit, p. 38-39, 41-43.

53 Wills, op. cit, p. 38-45.

54 I. C. Brown, "Hume's Skepticism and the Weight of History", History Today, num. 31, 1981, p. 40-45; David F. Epstein, The Political Theories of the Federalist, Chicago, University of Chicago Press, 1984, p. 68-76.

55 Fletcher Wright, op. cit, núm. 10, p. 131.

Ibidem, núm. 6, p. 111. 
discutir la mayoría, los autores tenían en mente a las masas, los pobres, los deudores y las clases pequeñopropietarias. Se referían a la protesta que estaba enraizada en el descontento economico de esas clases durante el periodo de laConfederacion. Apuntando a Daniel Shays, quien dirigió una rebelión en el occidente de Massachusetts en 1787, Publius escribio: "Si Shays no hubiera sido un deudor desesperado, es muy dudoso que Massachusetts se hubiera lanzado a una guerra civil." Los federalistas temían de aquellas clases, su "rabia furiosa" por hacer que se abolieran las deudas, que se llegara a una división igualitaria de la propiedad, o por cualquier otro proyecto "indecoroso o malvado". 57

El deseo de los federalistas era el de frenar levantamientos tales como la rebelión de Shays, y el de limitar el espíritu popular de 1776. Representaban a las élites minoritarias que consideraban los actos populares del momento como acciones anticonstitucionales amenazantes para las instituciones, y como una revolución tiránica perpetua. ${ }^{58} \mathrm{En}$ su ansiedad de preservar su elevada posición económica, social y política en la sociedad, los federalistas no permitirían que "la fuerza superior de una mayoría interesada e imperiosa" llegara a controlar a "las minorías". 59

Por lo tanto, el reto para los tratadistas de la Constitución era el restringir las tendencias populares extremas y prevenir la "tiranía" de las mayorías. Primero, los federalistas criticaron las legislaturas estatales en la cuales, de acuerdo con el pensamiento constitucional del momento, los representantes eran los únicos agentes de los deseos del pueblo. Pero, en opinion de los federalistas, las legislaturas se aprovechaban de su posición de representantes exclusivos y demandaban poderes ilimitados. Más aún, afirmaban los federalistas, las legislaturas estaban ocupadas por miembros oscuros e ignorantes, los cuales eran peligrosos para la comunidad total. De esta forma, los federalistas sugerían tanto balancear el poder de las legislaturas, como ocuparlas con miembros de las clases altas, arguyendo que el liderato político pertenece naturalmente a las elites más hábilmente educadas, experimentadas y ricas. ${ }^{60}$

Además, los Ensayos federalistas proponian que el papel del gobierno no fuese solamente el de promover el bienestar colectivo del pueblo. El gobierno debería también proteger las libertades de la minoría, es decir, de las elites, en contra del atropello de la facción mayoritaria. ${ }^{61} \mathrm{La}$ base logica de los autores para el derecho de la minoría era la protección de las libertades individuales: " $\mathrm{El}$ asegurar el bien común y los derechos privados frente al peligro de una determinada facción, y al mismo tiempo preservar el espíritu y la forma de gobierno popular es, entonces, el gran objetivo hacia el cual se dirigen nuestras indagacio-

57 Ibidem, núm. 6, p. 110; núm. 10, p. 136.

58 Wood, op. cit., p. $319-328,409-413,475-483$.

59 Hofstadter, "The Founding Fathers", p. 4, 8; Wood, op. cit., 475-483; Martin Diamond, "The Federalist", en Leo Strauss et al., History of Political Philosophy, Chicago, Rand McNally \& Co., 1963, p. 647; Fletcher Wright, op. cit., núm. 10, p. 130. Este artículo no entra a la controversia clásica de la "interpretación económica de la Constitución" que Charles Beard inició. Véase Charles A. Beard, An Economic Interpretation of the Constitution of the United States, Nueva York, Macmillan Company, 1913. Una respuesta importante al trabajo de Beard es el de Robert. E. Brown, Charles Beard and the Constitution: A Critical Analysis of "An Interpretation of the Constitution", Princeton, Princeton University Press, 1956, y el de Forrest McDonald, We the People: The Economic Origins of the Constitution, Chicago, Chicago University Press, 1958.

60 Wood, op. cit., p. 506-518.

61 Diamond, Notes on Political Theory, p. 9; Diamond, "The Federalist", p. 642. 
nes." ${ }^{62}$ El reto de la Constitución era lograr la libertad del individuo y de la minoría, junto con orden y autoridad.

Para que el gobierno asegurara la posición de las elites, los federalistas tenían que encontrar las formas de estabilizar el gobierno. Creían que restringir las malas tendencias de la gente era la clave para lograr estabilidad. Correspondía a la Constitución controlar las tendencias destructivas de los hombres en relación con la autoridad, instituciones y liderazgo. A pesar de todo, el papel que la Constitución Federal asignaba al gobierno no era el de un ajuste imposible de las facciones al bien común. Ateniéndose a la realidad, los tratadistas pensaron que el gobierno puede permanecer estable más bien ajustándose a la naturaleza humana y controlando solamente sus peores manifestaciones: "el alivio tiene que ser buscado únicamente en los medios de controlar los efectos [malos de la naturaleza humana]", lo cual es la "tarea principal de la legislación moderna". Esta idea fue un producto de la década de los años 1780 , y reducía la creencia en la virtud pública, incrementando el entendimiento de que la sociedad está compuesta por una variedad de intereses conflictivos. No había escape para los federalistas, sino aceptar la existencia de facciones e intereses en la sociedad, a pesar de su ansiedad creciente de proteger la posicion de la elite.

La solución que los Ensayos ofrecían era dar garantías políticas a la naturaleza humana. A pesar de que esta noción pudo haberlos llevado a imponer fuertes limitaciones a las libertades de las gentes, los federalistas permanecieron en gran medida leales al legado revolucionario de imponer restricciones al gobierno. ${ }^{65}$ También trataron de disponer un legado democrático republicano, de acuerdo con el cual el poder último residiría en el pueblo:

La genialidad de la libertad republicana parece demandar, por una parte, no sólo que todo el poder se derive del pueblo, sino que quienes están investidos de él se mantengan dependientes del pueblo. ${ }^{66}$

\section{Sobre republicanismo y libertades}

Los autores de los Ensayos federalistas argumentaban que el concepto del republicanismo representativo se ajustaba a los principios del gobierno popular. Era importante contestar las acusaciones antifederalistas de que el documento propuesto era antidemocrático. Los Ensayos federalistas, por lo tanto, trataban al republicanismo como una forma democrática, como otra forma de gobierno de las mayorías, diferente de las formas de gobierno de las minorías o del dirigido por un solo individuo. Los autores clasificaban al gobierno republicano como democrático, a pesar de que, como según admitían ellos mismos, algunos de sus rasgos se alejaban de la "democracia pura". Primeramente, Publius clasificó sus términos: la "democracia pura" era definida como "una sociedad que consiste en un número pequeño de ciudadanos, quicnes se reúnen y administran el gobierno en persona", como los Estados del

62 Fletcher Wright, op. cit., nüm. 10, p. 132.

63 Wood, op cit., p. 219-222, 606-613; Bronson, op cit., p. 235-250.

64 Fletcher Wright, op cit., núm. 10, p. 130-132.

65 Hofstadter "The Founding Fathers", p. 6.

66 Fletcher Wright, op cit., núm. 37, p. 268.

67 Diamond, "The Federalist", p. 635, 637-638; Mace, op cit., p. 103. 
mundo antiguo. 68 En una república, en contraste, la gente "se reúne y administra... [el gobierno] a través de sus representantes y agentes".69 Esto es para decir que una república es una democracia representativa.

Los Ensayos federalistas concebían la finalidad de la Constitución como "un remedio republicano para las enfermedades más incidentes del gobierno republicano". ${ }^{70}$ En otras palabras, más que sustituir la democracia pura por la forma superior de republicanismo, los federalistas deseaban crear una nueva forma ideal de republicanismo que perfeccionaría todas las formas republicanas conocidas hasta entonces. La Constitución, esperaban, introduciría "medios poderosos para conservar las excelencias del gobierno republicano y disminuir y evitar sus imperfecciones". 71

Pero primero Publius tenía que demostrar las ventajas de una república en relación con una "democracia pura". El problema con las democracias, decían los autores, es que, según la experiencia histórica,

no pueden admitir ninguna cura a los dafios causados por la facción. Una pasión o interés común será sentida, casi en cada caso, por una mayoría ... y no hay nada que contenga los incentivos al sacrificio del partido más débil, o a un individuo nocivo. De ahí que tales democracias siempre han sido espectáculos de turbulencias y contiendas ... y sus vidas han sido en general tan cortas como han sido violentas sus muertes. 72

La clave de la suerte que tales democracias habían corrido, explicaban los Ensayos federalistas, eran las libertades completas otorgadas a la gente, que permitían el crecimiento de facciones mayoritarias destructivas.

El problema que los federalistas enfrentaban era su pérdida de confianza en la gente que les impedía proporcionarle el acceso al poder. Querían incrementar el poder de las instituciones e introducir mecanismos constitucionales para limitar el poder de los individuos, al mismo tiempo que para preservar principios democráticos. Su solución se encontraba en cambiar el principio de soberanía. Publius observo en Hobbes la idea de lograr el interés común a través de la búsqueda que la gente emprendería para encontrar intereses privados que al mismo tiempo la comprometerían: "la gente debe ceder [al gobierno] algunos de sus derechos naturales, para investirlo con los poderes imprescindibles" y luego limitar el faccionarismo. ${ }^{73}$ La gente limita al gobierno para que no ejercite un poder total, mientras que el gobierno restringe algunas de las libertades de la gente, con su consentimiento. Lo que hace que ese arreglo perdure es la autoridad que las personas conceden al gobierno para que dirija sus vidas. En esta forma promueven ellas el bienestar común y al mismo tiempo preservan sus libertades fundamentales. ${ }^{74}$

Esta idea se hizo posible al asentar la Constitución la soberanía en el pueblo en general. Cada ciudadano por separado y todos ellos juntos son igualmente soberanos. La soberanía es una e indivisible. Esta nocion de

74 Mace, op cit, p. 7, 60-62, 81, 88-91; Draper, op cit., p. 47. 
soberanía pópular reemplazó la idea de un contrato entre gobernante y gobernado. Ya no es el gobernante soberano quien otorga al pueblo sus derechos. ${ }^{75}$

De acuerdo con el principio de soberanía popular, la representación del pueblo en las instituciones gubernamentales incluye teóricamente a todos los ciudadanos. Sin embargo, en realidad, y los Padres Fundadores así lo reconocieron, la representación sólo puede ser un intento parcial, pues nunca es posible representar a cada ciudadano o grupo. De forma que los Padres Fundadores aprobaron constitucionalmente una representación que en la práctica se encuentra sólo en las manos de unos pocos. Esto presentó un cambio en la antigua sospecha referida a tal idea teórica de representación parcial. Fueron los whigs radicales quienes basaron la ideología revolucionaria en la falta de representación de las Colonias en el Parlamento de Londres. ${ }^{76}$ Los tratadistas de la Constitución, en vez de esto, argumentaron que la práctica propuesta no dañaría los derechos del pueblo:

La totalidad de los poderes del gobierno propuesto va a estar en manos de los representantes del pueblo. Esto es esencial, y después de todo, solamente seguridad eficaz para los derechos y privilegios del pueblo. ${ }^{77}$

Preservar los derechos del pueblo puede lograrse al otorgar éste el poder al gobierno, lo cual se hizo posible por el nuevo concepto de soberanía popular. Los soberanos delegan su poder colectivo y su capacidad soberana en sus representantes, quienes dirigen el gobierno. Así los gobernantes y los representantes se convierten en los representantes del pueblo. El pueblo mismo no tiene que participar en la práctica del gobierno, sin embargo, no pierde por ello su poder. El pueblo controla continuamente el gobierno con el poder de su soberanía completa: otorga su soberanía a la Constitución, y la Constitución da instrucciones sobre los límites impuestos al gobierno y a la autoridad de los representantes, ${ }^{78}$

Este sistema indicaba el rechazo del pueblo norteamericano a sacrificar demasiadas libertades ante las autoridades: "no podría haber mayor locura que abolir la libertad, la cual es esencial para la vida política". Sería como la "aniquilación del aire, esencial para la vida animal". 79 Sin embargo, al mismo tiempo, a través del pacto, el pueblo otorga su soberanía al gobierno de tal manera que éste refrenda la legitimidad recibida ejerciendo a su vez el poder sobre el mismo pueblo. Por este mecanismo, la Constitución justifica el control del hombre sobre el hombre: de los representantes sobre el pueblo.

Los Padres Fundadores sabían que aun un sistema republicano perfeccionado no podría erradicar el espíritu de facción completamente. Sin embargo, demostraron cómo utilizaría la nueva maquinaria precauciones auxiliares para controlar la naturaleza del hombre. La Constitución proponía un gobierno que no necesitase depender de la frágil razón y sabiduría humanas:

¿Qué es el gobierno en sí, sino la más grande de todas las reflexiones de la naturaleza humana? Si los hombres fueran ángeles, no habría necesidad de go-

75 Wood, op. cit., p. 268-282, 383-389.

76 Ibidem.

77 Fletcher Wright, op. cit., núm. 28, p. 224.

78 Diggins, op. cit, p. 56-57; Wood, op. cit, p. 593-600.

79 Fletcher Wright, op. cit, núm. 10, p. 130. 
biernos. Si los ángeles fueran a gobernar a los hombres, no serían necesarios controles externos ni internos en el gobierno. Una dependencia en relación con el pueblo es, sin lugar a dudas, el control primario del gobierno; pero la experiencia ha enseffado a la humanidad la necesidad de precauciones auxiliares ... uno debe primeramente permitir al gobierno que controle a los gobernados. 80

Si realmente los hombres no pueden convertirse en ángeles, y si el gobierno a pesar de todo tiene que depender de ellos, es mejor utilizar las tendencias negativas del pueblo, en vez de buscar la virtud en vano.

Los federalistas preferían líderes de la elite, personas "cuya sabiduría pueda discernir mejor los verdaderos intereses de su país, y cuyo patriotismo y amor de justicia les hará menos probable sacrificarlo a consideraciones parciales o temporales". 81 Deberían ser hombres seleccionados, los "más sabios, sistemáticos y prudentes ... y en consecuencia, más satisfactorios" que los "políticos facciosos que actualmente asumen el liderato del pueblo". ${ }^{82}$ Los federalistas, por lo tanto, pensaron en infiltrar a los representantes por medio de elecciones populares, las cuales no permitirían el acceso a los cuerpos gubernativos a individuos malamente motivados. El pueblo podría elegir correctamente, juzgando la reputación del candidato, y así eliminaría las posibilidades de demagogia extrema para movilizar el apoyo: ${ }^{83}$ "siendo los sufragios del pueblo más libres, el pueblo se centrará con más probabilidad en hombres que poseen el mérito más atractivo y los más difusos y establecidos caracteres". 84

Mas si el encontrar mejores líderes resulta difícil, los tratadistas de la Constitución ofrecían una capacidad de gobierno singular para institucionalizar las pasiones. Publius observó que algunas pasiones pueden ser consideradas útiles si las instituciones las utilizan adecuadamente. Rasgos tales como el orgullo, la vanidad, la ambición de poder, fama y gloria, proponían los Ensayos federalistas, pueden utilizarse en el proceso electoral. El mecanismo de las elecciones puede alentar a ciertas personas como posibilidad de encontrar sastisfacción a tales intereses, pero al mismo tiempo obrará positivamente al lograr que esas personas sirvan como conductores de sus compatriotas. Dada la necesidad egoísta de ganar amplio apoyo popular, esos líderes tendrán que promover el interés público. Tendrán que apegarse a los intereses de la comunidad en su totalidad y que abstenerse de actuar en favor de facciones particulares para ser electos. De esta forma el egoísmo puede hacer que quienes tienen puestos públicos funcionen bien mientras satisfacen simultáneamente los intereses del público y los suyos propios. 85

Otro mecanismo que la Constitución proponía para conseguir el interés público fue una extensa estructura de la república. Los Ensayos federalistas describían el mecanismo de una república extensa como "la extensión de la órbita" o la "consolidación de los estados", en contraposición de la "república confederada actual" o la "reunión de sociedades". ${ }^{86}$ La idea era abolir la independencia de los estados y unirlos 
en una gran unión federal. La tradición de la Ilustración, sin embargo, favorecía pequeñas repúblicas basadas en las propuestas por Montesquieu, quien se refería a una república más pequeña que cualquiera de los estados norteamericanos. Los enemigos de la Constitucion también apoyaban unidades políticas restringidas, arguyendo que su ampliación violaría las libertades. Grandes países, decían, se vuelven naturalmente despoticos, pues "la necesidad de poder crece para controlar un Estado más grande". Así, pues, los antifederalistas se oponían a las grandes estructuras por considerarlas como necesariamente antirrepublicanas. ${ }^{87}$

No era entonces un asunto trivial para los tratadistas de la Constitución argüir radicalmente en contra de la establecida noción de una república limitada. La ventaja clave de una república más extensa, explicaban los Ensayos federalistas, descansaba en el incremento de la población del país. Una población numerosa ayudaría a seleccionar el tipo correcto de representantes:

Cada representante será escogido en la república grande por un número mayor de ciudadanos que en la pequeña, y será más difícil para candidatos indignos el practicar con éxito las artes perversas con las cuales las elecciones se llevan a cabo frecuentemente. ${ }^{88}$

\section{En un sistema nacional amplio}

serán necesarios una reputación más general y extensa y otros requisitos para seffalar a determinados individuos como candidatos para ocupar puestos públi$\cos$... más aún, dado que se tendrá un campo más amplio para la elección, nunca se experimentará esa necesidad de personas apropiadas, la cual no es infrecuente en algunos de los estados. 89

Lo que parecía aún más importante para los federalistas, era que una república grande incrementaría el número de intereses que estarían operando en la sociedad, mientras que eliminarían su potencial destructivo y ocasionalmente los balancearía. La idea era multiplicar el número de facciones en un Estado grande, más bien que reducirlas en muchos Estados pequeños y separados. El pensamiento era también disminuir los intereses del pueblo al usarlos eficazmente uno contra otro, más que una creencia ilusoria en que los intereses enfrentados podrían erradicarse. Este concepto de una variedad de facciones puede ser descrito como "pluralismo". Su ventaja, en la mente de los federalistas, era que podía evitar un cisma, reacción típica de las facciones donde existen en menor número, pero con unas proporciones mayores. Los sistemas políticos con pocas facciones son más peligrosos por su extremismo e irracionalismo, demostrado por sus líderes, y las oportunidades de que una de las facciones pueda ganar el control completo y dirigirse hacia la tirania. 90

La noción de un pluralismo en una república amplia era elemento

87 Diggins, op. cit, p. 35-36; Diamond, "The Federalist", p. 635-636.

88 Fletcher Wright, op. cit., núm. 10, p. 134.

89 Ibidem, núm. 3, p. 98.

90 Esta idea también fue adoptada por Publius de Hume. Al criticar a Montesquieu, Hume argüía que las pequeñas repúblicas hacen surgir el problema de divisón en pequeños partidos y que la proximidad de los habitantes es peligrosa puesto que las masas pueden usar al gobjerno para controlar a la minoría. En una república grande, sin embargo, escribió Hume, las partes son lo suficientemente diversificadas como para prevenir tales fenómenos. Véase Adair, "Politics", p. 98-102 
crucial en el pensamiento de los Padres Fundadores con respecto a la "separación de poderes", cuyo significado era "la distribución regular de poder en departamentos distintos": ejecutivo, legislativo y judicial. 91 Constitucionalmente, ninguno de los cuerpos es soberano, lo cual los hace iguales y sin prerrogativas uno sobre otro. De esta manera controlan y balancean unos con otros las ambiciones de un poder excesivo. Esas "restricciones y balanceos" en el gobierno establecerían que

la gran seguridad en contra de una concentración gradual de los varios poderes en el mismo departamento, consiste en dar a aquellos que administran cada departamento los medios constitucionales y motivos personales necesarios para resistir la ursupación de los otros. 92

Durante la era de la Confederación, el principio de separación de poderes funcionaba de acuerdo con las constituciones de los estados. Su propósito era el de mantener a la legislaturas y judicaturas aisladas y protegidas de las manipulaciones de los ejecutivos. Pero los federalistas querían más bien controlar el poder de la legislatura, cuya conducta juzgaban desenfrenada y abusiva, y permitir más poderes al ejecutivo. ${ }^{93} \mathrm{Co}$ mo Publius representaba a las legislaturas como facciones, era coherente al articular su argumento en apoyo de la separación de poderes aplicando el concepto de espíritu de facción en las otras ramas: si cada una se percibe como una facción, su egoísta inclinación a privar a los ciudadanos de sus derechos está controlada y balanceada por la competencia interdepartamental. En este sentido, el "pluralismo" en el gobierno garantiza el poder al ejecutivo, sin dañar las libertades.

\section{Sobre los estados y la Union}

Finalmente, los Ensayos federalistas defendían una república de mayor extension, arguyendo que una forma de unión grande y cohesiva disminuiría el peligro de inestabilidad en cada uno de los estados: "Una Unión firme será de la más grande importancia para la paz y la libertad de los estados, como barrera en contra de la facción doméstica y de insurreccion". Los federalistas temían el desorden político y la opresión de la minoría en los estados. Tenían terror a la inevitable anarquía, tiranía y pérdida de libertades civiles que se produciría en los estados y que se difundiría por toda la Unión. La situación, afirmaban, era resultado del control político en manos de políticos de miras estrechas en asambleas estatales no confiables, que se rehusaban a cooperar con el gobierno central.

Publius describía su preocupación en estas palabras:

La intolerancia puede alzar su cresta en cada estado [amenazando] las libertades del pueblo, mientras que el gobierno nacional no podría legalmente hacer nada, más que contemplar sus abusos con indignación y pesar. Una facción con éxito puede erigir una tiranía sobre las ruinas del orden y de la ley, mientras

91 Fletcher Wright, op. cit., núm. 9, p. 134.

92 Wood, op. cit., p. 446-453; Diamond, "The Federalist", p. 643-645.

93 Wood, op. cit, p. 268-282; Diamond, "The Federalist", p. 645; Mace, op. cil., p. 117. 113.

94 Fletcher Wright, op. cit, núm. 9, p. 124. 
que ningún socorro podría ser constitucionalmente proporcionado por la Unión a los amigos y partidarios del gobierno. 95

Cada estado, cediendo a la persuasiva voz del interés o conveniencia inmediatos, ha retirado con éxito su apoyo, hasta que el frágil y tambaleante edificio parece listo para caer sobre nuestras cabezas y enterrarnos bajo sus ruinas.

Seremos empujados a la alternativa ya sea de tomar refugio de inmediato en los brazos de la monarquía, o de dividirnos en una infinidad de pequeñas, celosas, conflictivas, tumultuosas repúblicas, miserables invernaderos de discordia incesante y objetos dignos de lástima o desprecio universales. 9 ?

Había, entonces, el peligro de una total destrucción de los Estados Unidos como consecuencia de la falta de algo mejor que una unión débil e insegura.

La solución de los Padres Fundadores era que los estados se controlaran y balancearan al someter su soberanía a la Unión. La Constitución aniquilaría la soberanía de los estados y la cedería, mediante el pueblo, a la Unión y su gobierno federal. Los estados serían "partes integrantes de la soberanía nacional". ${ }^{98}$ La Constitución, sin embargo, estaba "lejos de implicar una abolición de los gobiernos estatales". 99 En lugar de abolir a los estados como unidades políticas, los autores de los Ensayos federalistas proponían aprovecharlos en una nueva estructura federativa. Su idea era utilizar la competitividad de los estados, mientras que el gobierno federal, como una autoridad soberana central, conciliaría sus intereses para beneficio de la Unión: "disfruta la Unión sobre los estados que la componen la misma ventaja que la república tiene sobre la democracia, al controlar los efectos de la facción". ${ }^{100}$

Publius quería decir que es en el nivel federal donde el bien común se aprecia mejor:

El panorama de perdida actual o ventaja puede con frecuencia tentar al partido gobernante en uno o dos estados a desviarse bruscamente de la buena fe y de la justicia; pero esas tentaciones, al no alcanzar a los otros estados, y teniendo consecuentemente poca o ninguna influencia en el gobierno nacional, se verían limitadas en sus alcances, y la buena fe y la justicia se preservarán. ${ }^{101}$

La Constitución "forma una feliz combinación en este sentido, relegando los grandes y globales intereses a la legislatura [nacional] y local y particular a las legislaturas estatales". ${ }^{102}$ La responsabilidad del gobierno federal en el manejo de los asuntos más generales, dejando los asuntos locales y menos cargados políticamente a los estados, relajaría las tensiones entre ellos. Tomar las decisiones importantes en el centro no solo cancelaría inconsistencias en los estados, sino que "la administración, los consejos políticos y las decisiones judiciales del gobierno nacional serán más sabias, sistemáticas y juiciosas que las de los estados individuales". 103 
Por encima de todo, los federalistas estaban preocupados acerca de la carencia de una autoridad legítima sobre los estados en el gobierno central. El hecho de que el Congreso de la Confederación necesitara consentimiento de cada estado para imponer su legislación, privaba al Congreso de autoridades vitales:

el proximo defecto probable subsistente en la Constitución es la falta total de castigo en sus leyes. Los Estados Unidos como están compuestos ahora, no tienen poderes para imponer obediencia, o castigar la desobediencia a sus resoluciones, ya sea de modo pecuniario o de cualquier otro modo constitucional. No hay una delegación explícita de autoridades para usar la fuerza en contra de los transgresores. ${ }^{104}$

Los defectos del sistema de soberanía confederativo estatal no afectaron solamente a la autoridad en los estados. Más aún, la residencia de la soberanía en los estados no permitía al Congreso hacer valer su autoridad sobre los individuos. Esto era problemático, particularmente en relación con individuos o grupos en rebelión, los cuales se sentían excluidos de la comunidad establecida. Publius expreso la necesidad de cambio: "debemos extender la autoridad de la Unión a los ciudadanos -los únicos objetos propios de gobierno". ${ }^{105}$ El quería decir que había necesidad de un mecanismo constitucional para abolir la interferencia entre el gobierno nacional y los ciudadanos como individuos, lo cual, para los federalistas, era la última garantía de autoridad.

Mediante la devolución de la soberanía de los estados al pueblo, la Constitución resolvió el problema de legitimidad del gobierno. Ya no habría espacio para protestas y críticas de autoridad provenientes de que los sentimientos del pueblo habían sido omitidos de la comunidad. La soberanía popular redefinía el contrato social. Determinaba a la comunidad política norteamericana como unidad compacta en la cual todos los ciudadanos como soberanos pertenecían igualmente a la comunidad política. Como colectivo, el pueblo de los Estados Unidos otorgaba voluntariamente su soberanía a la Constitución. Así, todos los individuos organizados en unidad compacta elegían obedecer a la Constitución. También escogían obedecer al gobierno y las leyes derivan sus poderes de ésta. 106 Así pues, la nueva legitimidad está anclada en un triángulo interdependiente de soberanía: el pueblo, el gobierno y la Constitución.

La completa dependencia de los federalistas de una solución constitucional como una garantía del orden indica un cambio en el pensamiento político en la segunda mitad del siglo XVIII. Debido a Montesquieu y a Rousseau, el nuevo enfoque fue el de una constitución como documento cuyas facultades estarían por encima de la ley ordinaria; es decir, constitucional, a diferencia de legal, referido a un conjunto superior de principios independiente de cualquier institución gubernativa. No sólo porque tales instituciones pueden no ajustarse o alterar leyes constitucionales como pueden hacerlo con leyes ordinarias, sino

104 Ibidem, núm. 21, p. 186: "the next probable defect of the subsisting Constitution, is the total want of sanction to its laws. The United States as now composed, have no powers to exact obedience, or punish disobedience to their resolutions, either by pecuniary, or by any other constitutional mode. There is no express delegation of authorities to them to use force against delinquent members".

105 lbidem, núm. 15, p. 159.

106 Wood, op. cit., p. 471-475; Arieli, op. cit., p. 33-37. 
porque las instituciones deben regular sus propias decisiones y su legislación sustentándose en la Constitución. 107

Buscando un largo y duradero orden, la Constitución federal fue ideada por sus tratadistas como un conjunto supremo de principios sagrados y permanentes. A diferencia de leyes ordinarias que son de una naturaleza ordinaria, la Constitución es inmodificable. Por esta razón, y para institucionalizar la confianza fundamental de la comunidad en su Constitución, tuvo que ser ratificada unánimemente por todos los estados. Ya que-las legislaturas existentes carecían de legitimidad, el proceso de ratificación requirió la utilización de cuerpos extralegislativos como convenciones ratificadoras, las cuales fueron consideradas legítimas por todos los ciudadanos. Esto simbolizaba la nueva soberanía popular de facto, tanto para los contemporáneos como para las generaciones futuras.

\section{Conclusión: sobre cómo prevenir la destrucción total}

Los Ensayos federalistas aclararon que la preocupación de sus autores no terminaba con los daños que los Artículos de la Confederación causaban a las libertades civiles, al interés público y al orden político y social. El peligro final, como lo subrayaron, era el derrumbamiento total de la Unión. El creciente espíritu de facción tanto en los estados como entre ellos, disminuía su fuerza para mantener la paz interna. El mayor peligro, según ellos, era que las rivalidades trajeran una guerra civil doméstica que necesariamente debilitaría las fuerzas de la Unión para protegerse de poderes extranjeros hostiles.

El sistema existente, aquellos estados fronterizos cuyos poderes se extendían al exterior, podían ser empujados a una guerra abierta e involucrar a toda la Unión en ella. El peligro no era solamente que los estados separados fueran correctamente vistos por el enemigo como débiles y desunidos: más peligrosa aún era la incapacidad del gobierno central de llevar a cabo políticas de defensa, diplomacia y negociaciones de paz, y entrenar y disciplinar a un ejército unido capaz de defender a todos los estados al mismo tiempo. ${ }^{108}$ Así, escribio Publius, sólo un gobierno federal nacional

puede moverse con principios políticos uniformes. Puede armonizar, asimilar y proteger las varias partes y miembros, y extender el beneficio de su previsión y precauciones a cada uno de ellos. En la formulación de tratados, tomará en cuenta los intereses del todo, y los intereses particulares de las partes en su conexión con el interés del todo. Puede aplicar las razones y el poder del todo a la defensa de cualquier parte particular ... Puede colocar a la milicia bajo un plan de disciplina ... y consolidar las partes en un solo cuerpo, y de ese modo hacerlas más eficientes que si estuvieran divididas. ${ }^{109}$

Publius aprendió de varios ejemplos históricos los peligros que esperaban a las repúblicas facciosas. Los Estados Unidos, advirtió, alcanzarían el destino de las antiguas "repúblicas insignificantes" de Grecia y Roma. Su historia, escribió Publius, no puede ser leída

107 Wood, op. cit, p. 259-268, 403-409; Martyn P. Thompson, "The History of. Fundamental Law in Political Thought from the French Wars of Religion to the American Revolution”, en American Historical Review, núm. 91, 1986, p. 1125-1128.

108 Ibidem, núm. 4, p. 103-104.

109 Ibidem, núm. 4, p. 102-103. 
sin sensaciones de horror y de disgusto al ver las distracciones que las agitaban continuamente, y al ver la rápida sucesión de revoluciones con las cuales se mantenían en un estado de oscilación perpetua entre los extremos de la tiranía y de la anarquía. ${ }^{110}$

Para que su opinión acerca de la destrucción potencial de la Unión norteamericana fuera convincente, los autores de los Ensayos federalistas hicieron un estudio de varias "repúblicas" historicas sin éxito. Se extendieron desde el Periodo Clásico hasta la Edad Media, concluyendo con ejemplos recientes del siglo XVIII: en Grecia, la Liga Griega de Repúblicas Soberanas, asociadas al Consejo Anfictiónico; ${ }^{111} \mathrm{el} \mathrm{Im-}$ perio Alemán Medieval; 112 la Unión Suiza de Cantones, y otras confederaciones, tales como la holandesa, la polaca y la belga.113 Todas éstas, concluían los Ensayos federalistas, no habían escapado al destino de desintegración completa.

La causa fundamental común de su destrucción había sido la carencia de un sistema constitucional más complejo. Estas alianzas fueron limitadas en cuanto al pensamiento constitucional, pues habían sido formadas, ya sea para propositos de guerra y defensa o por lazos tradicionales, pero no para promover una amplia gama de bienestar en los individuos y en la comunidad. La simplicidad constitucional no había permitido que un gobierno legítimo central y capaz funcionara, eliminando a la larga la capacidad para sobrevivir de las confederaciones. De esta forma, tal como lo demostrara un ejemplo, el gobernante había sido forzado a luchar junto con la mitad de su imperio en contra de la otra mitad, la cual se había aliado con el enemigo. En otros ejemplos las rivalidades entre los estados terminaron en la opresión de los estados débiles por los estados fuertes, lo cual ayudaba a enemigos externos a conquistar a toda la Unión.

Otro problema constitucional con esos estados históricos era que, a pesar de que generalmente se habían autonombrado "repúblicas", no lo eran. Sus representantes eran nominados por consejos o gobernantes, más bien que elegidos por el pueblo. De esta manera, la falta de un republicanismo genuino no había permitido a las instituciones del gobierno derivar el poder directamente de cada ciudadano, por lo que el gobierno se hallaba impotente en sus intentos de poner en vigor la autoridad legítima sobre los ciudadanos.

En respuesta a sus hallazgos, los autores de los Ensayos federalistas concluyeron que la historia de casi todo

gran consejo y consultas que se celebraban entre la humanidad para conciliar sus opiniones discordantes, apaciguando sus celos mutuos y ajustando sus intereses respectivos, es una historia de facción, de pretensión, de contiendas y decepciones, que puede ser clasificada entre las imágenes más oscuras y degradadas que exponen las flaquezas y perversiones del caracter humano. 114

Históricamente, resumían los federalistas, el mantener con éxito unidades políticas interrelacionadas y soberanas no era sino una utopía:

110 lbidem, núm. 9, p. 124.

111 Ibidem, núm. 18, p. 171-175.

112 Ibidem, núm. 17, p. 169-170; núm. 19, p. 177-179.

113 Ibidem, núm. 19, p. 180-181; núm. 20, p. 182-185.

114 Ibidem, núm. 36, p. 271. 
El buscar una continuación de armonía entre un número de soberanías independientes desconectadas de sus mismos vecinos, sería ignorar el curso uniforme de los acontecimientos humanos, y desafiar la experiencia acumulada durante siglos. 115

Con la esperanza de evitar un destino desgraciado, los federalistas hicieron un llamado al pueblo norteamericano, especialmente a los adversarios de la Constitución, a despojarse de la irracional creencia en una Unión dividida. Más aún, la unidad no era un asunto político solamente. Era también una cuestión de preservar a la nación norteamericana como pueblo unido por un pasado y tradiciones comunes, cuya misión era permanecer unido:

La Providencia ha tenido la satisfacción de otorgar este pars unido a un pueblo unido - un pueblo que desciende de los mismos ancestros, que habla el mismo idioma, que profesa la misma religion, sujeto a los mismos principios de gobierno, muy parecido en sus usos y costumbres, y que, por sus consejos, armas y esfuerzos conjuntos, luchando lado a lado en una larga y sangrienta guerra, ha establecido noblemente una libertad general e independiente. ${ }^{116}$

Al adoptar la nueva Constitución federal, los autores de los Ensayos afirmaron que todos los norteamericanos tendrían el privilegio de conseguir libertades individuales, estabilidad y comunidad. La Constitución, como se prometía en los Ensayos federalistas, no podía equivocarse. Estaba construida sobre principios universales sólidos, confirmados por una larga experiencia histórica. La experiencia, mantenían los autores, es "el oráculo de la verdad; y puesto que sus respuestas son inequívocas, deben ser decisivas y sagradas". 117 